\title{
Regulation of Bacteroides fragilis katB mRNA by Oxidative Stress and Carbon Limitation
}

\author{
EDSON R. ROCHA AND C. JEFFREY SMITH* \\ Department of Microbiology and Immunology, East Carolina University, Greenville, North Carolina 27858
}

Received 22 May 1997/Accepted 3 September 1997

\begin{abstract}
Regulation of the katB catalase gene in the anaerobic bacterium Bacteroides fragilis was studied. Northern blot hybridization analyses revealed that $k a t B$ was transcribed as an approximately 1.6-kb monocistronic mRNA. The levels of $k a t B$ mRNA increased $>15$-fold when anaerobic, mid-logarithmic-phase cultures were exposed to $\mathrm{O}_{2}, \mathrm{O}_{2}$ with paraquat, or hydrogen peroxide. Under anaerobic conditions, the low levels of katB mRNA increased in a growth-dependent manner, reaching maximum expression at late logarithmic or early stationary phase, followed by a decrease in stationary phase. Under anaerobic conditions, the expression of $k a t B$ mRNA was strongly repressed by glucose and to a lesser extent by xylose. However, glucose repression was completely abolished upon exposure to oxygen. The nonfermentable carbon sources fumarate, succinate, acetate, and pyruvate did not significantly affect expression. Phosphate, nitrogen, and hemin limitation did not affect the expression of $\mathrm{katB}$ mRNA, suggesting that the nutritional control of $\mathrm{katB}$ expression is restricted to carbon and energy sources and not other forms of nutrient limitation. Primer extension analysis revealed that during both oxidative stress and carbon or energy limitation, katB utilized the same promoter region but transcription initiation occurred at two different nucleotides separated by 3 or 4 bases. Interestingly, a 6-bp inverted repeat sequence present in the katB regulatory region was also observed upstream of the $B$. fragilis superoxide dismutase gene sod. It is possible that this is a recognition site for a DNA binding protein involved in the regulation of oxidative stress genes in this organism.
\end{abstract}

Aerobic and facultative organisms have developed an efficient mechanism for protection against the reactive oxygen species (ROS) formed during aerobic respiration or during encounters with mammalian cellular defense mechanisms $(6,7$, 31). For example, superoxide anion is eliminated by superoxide dismutase and the accumulation of toxic hydrogen peroxide is prevented by catalases and peroxidases (9). Physiological adaptation to oxidative stress is typically complex and tightly regulated. This can be seen in the control of catalase synthesis which is an important component of the oxidative stress response. Hydroperoxidase I (HPI), KatG, of Escherichia coli is induced in mid-logarithmic-phase cultures by the presence of hydrogen peroxide (16). On the other hand, E. coli HPII, KatE, is induced following the onset of starvation at the beginning of stationary phase (16). The katG gene is transcriptionally regulated by the redox-sensitive regulator OxyR, which is also known to control at least 9 of the approximately 30 proteins that are induced with sublethal doses of hydrogen peroxide $(5,20)$, including alkyl hydroperoxide reductase $(a h p C F)$ and glutathione reductase (gor $A)$. Under reduced conditions, OxyR acts as a repressor, and under oxidative conditions, OxyR shifts and acts as a transcription activator (13, 32 ). Expression of katE is regulated by the alternative stationary-phase sigma factor RpoS (KatF) (22), a global regulator that controls the expression of several genes at the beginning of stationary phase $(14,17)$. The increase in catalase synthesis in response to either hydrogen peroxide or stationary phase protects microorganisms against high concentrations of hydrogen peroxide which would be lethal were it not for a previous adaptive response $(6,7)$.

Anaerobic bacteria such as Bacteroides fragilis are not gen-

* Corresponding author. Mailing address: Department of Microbiology and Immunology, East Carolina University, Greenville, NC 27858-4354. Phone: (919) 816-3127. Fax: (919) 816-3535. E-mail: jsmith@brody.med.ecu.edu. erally exposed to oxygen and/or ROS in the human intestine. However, when anaerobic bacteria are shifted from anaerobic to aerobic conditions, as may occur during the initial stages of infection, oxidative stress is unavoidable and an adaptive response for survival may occur in aerotolerant anaerobic bacteria. It is not yet known how aerotolerant anaerobic bacteria are able to survive in the presence of oxygen, but an earlier study with the pathogen $B$. fragilis showed that the presence of superoxide dismutase and catalase may help to protect the bacteria against the toxic effect of ROS (21). More recently, Rocha et al. (26) have shown that the oxidative response is more complex than just the synthesis of ROS scavenging enzymes, as a set of approximately 28 proteins are synthesized in $B$. fragilis upon either oxygen exposure or hydrogen peroxide treatment. One of these proteins was catalase, indicating that it is part of an oxidative stress response. B. fragilis appears to have a single catalase, which has been purified, and its gene, $k a t B$, has been cloned and sequenced (25). A katB mutant was shown to be sensitive to exogenous hydrogen peroxide compared to its parental strain, confirming that catalase may play a role in protection against hydrogen peroxide toxicity (26). Previous work has indicated that $B$. fragilis catalase increased upon exposure to either oxygen or hydrogen peroxide and that its enzymatic activity is highly repressed by the presence of fermentable carbohydrate $(8,26)$. Thus, the regulation of the single $B$. fragilis catalase appears complex, but the molecular mechanisms controlling its synthesis as well as the signals initiating it are not yet known. In this study, we present evidence that is consistent with transcriptional control of $B$. fragilis katB under a variety of growth conditions. These studies provide an initial look at the complex regulation of catalase in an anaerobic bacterium that is quite phylogenetically removed from the main line of bacterial descent. We hope that further studies may help us to understand how aerotolerant anaerobic bacteria survive in the presence of oxygen. 


\section{MATERIALS AND METHODS}

Strains and growth conditions. B. fragilis 638R (24) was grown routinely in supplemented brain heart infusion broth (contains $0.2 \%$ glucose [BHIS]) and incubated in an anaerobic chamber at $37^{\circ} \mathrm{C}(30)$. Peptone yeast extract broth medium (PY) (11) was supplemented with either $30 \mathrm{mM}$ glucose, $35 \mathrm{mM}$ xylose, $60 \mathrm{mM}$ acetate, $60 \mathrm{mM}$ pyruvate, $60 \mathrm{mM}$ succinate, or $60 \mathrm{mM}$ fumarate when required for experiments utilizing different carbon and energy sources. The chemically defined medium of Varel and Bryant (33) was used for nutrient limitation experiments in which $\mathrm{KH}_{2} \mathrm{PO}_{4},\left(\mathrm{NH}_{4}\right)_{2} \mathrm{SO}_{4}$, or hemin was the limited nutrient and added as indicated in the text.

Induction of oxidative stress in B. fragilis was carried out as previously described with some modifications (26). Briefly, oxygen exposure of the anaerobic cultures was carried out by splitting the cultures in two equal volumes. One half was placed on a rotatory incubator at $37^{\circ} \mathrm{C}$ and shaken at $250 \mathrm{rpm}$ in air for $1 \mathrm{~h}$, and the other half was kept in the anaerobic chamber for the same period. Treatment of cultures with paraquat was carried out as described above for oxygen except that $5 \mathrm{~min}$ after the cultures were divided, $500 \mu \mathrm{M}$ paraquat was added to both the anaerobic and aerobic cultures. Under the highly reducing, anaerobic conditions used to grow Bacteroides, it was thought that hydrogen peroxide would have a shorter half-life than in aerobic media. Thus, the peroxide response was induced by adding $50 \mu \mathrm{M} \mathrm{H}_{2} \mathrm{O}_{2}$ for $15 \mathrm{~min}$ twice. Then the challenge dose of $500 \mu \mathrm{M} \mathrm{H}_{2} \mathrm{O}_{2}$ was added 30 min before the cultures were harvested. The oxidant potassium ferricyanide $(20 \mu \mathrm{M})$ was also added to the culture medium for $30 \mathrm{~min}$ followed by the addition of $100 \mu \mathrm{M}$ or $1 \mathrm{mM}$ potassium ferricyanide for $30 \mathrm{~min}$ before the cultures were harvested.

RNA isolation and Northern blot analysis. Total RNA was isolated by the hot phenol method of Aiba et al. (1) as modified previously (27). Cultures were grown to mid-logarithmic phase $\left(A_{550}=0.3\right.$, approximately $1 \times 10^{8}$ to $2 \times 10^{8}$ cells $/ \mathrm{ml})$, unless indicated otherwise in the text. Chloramphenicol $(100 \mu \mathrm{g} / \mathrm{ml})$ was added to each culture, and the cultures were immediately centrifuged at $16,000 \times g$ for $10 \mathrm{~min}$ at $4^{\circ} \mathrm{C}$. After centrifugation, the cell pellet was suspended in $3 \mathrm{ml}$ of AE buffer ( $20 \mathrm{mM}$ sodium acetate [pH 5.5], $1 \mathrm{mM}$ EDTA, $0.5 \%$ [wt/vol] sodium dodecyl sulfate [SDS]), immediately extracted with $3 \mathrm{ml}$ of prewarmed phenol, and equilibrated with $20 \mathrm{mM}$ sodium acetate, $\mathrm{pH} 5.5$, at $65^{\circ} \mathrm{C}$. Extraction with phenol was carried at $65^{\circ} \mathrm{C}$ for $5 \mathrm{~min}$ and centrifuged at $12,000 \times g$ for $10 \mathrm{~min}$. Phenol extraction was repeated, and the final aqueous phase was precipitated with 3 volumes of $95 \%$ ethanol. Ethanol precipitation was repeated twice. The final RNA pellet was dissolved in either diethyl pyrocarbonate-treated water or deionized formamide and stored at $-70^{\circ} \mathrm{C}$. Concentration of total RNA was determined by measuring absorbance at $260 \mathrm{~nm}$.

RNA samples $(30 \mu \mathrm{g})$ were electrophoresed in $1 \%$ agarose gels containing $1 \times$ MOPS buffer [40 mM 3-( $N$-morpholino)propanesulfonic acid], and $2.2 \mathrm{M}$ formaldehyde (29). RNA size standards $(0.24$ to $9.5 \mathrm{~kb})$ (Life Technologies, Gaithersburg, Md.) were run in parallel. RNA was transferred to a nylon membrane (Hybond-N; Amersham Corp., Arlington Heights, Ill.) by capillary action in $20 \times$ SSC ( $1 \times$ SSC is $0.15 \mathrm{M} \mathrm{NaCl}$ plus $0.015 \mathrm{M}$ sodium citrate) and cross-linked by UV irradiation (29). The probe used for Northern blot analyses was a 790-bp $S p h \mathrm{I} / S s p \mathrm{I}$ internal DNA fragment of the $k a t B$ gene (25), labelled with $\left[{ }^{32} \mathrm{P}\right] \mathrm{dCTP}$ by random primer reaction with a commercial kit (Pharmacia LKB, Inc., Piscataway, N.J.). The blotted membrane was prehybridized for approximately $4 \mathrm{~h}$ in prehybridization solution $(50 \%$ deionized formamide, $3 \times$ SSC, $5 \times$ Denhardt's solution, $50 \mathrm{mM} \mathrm{NaH}{ }_{2} \mathrm{PO}_{4}$ [pH 7.0], $100 \mu \mathrm{g}$ of fragmented salmon sperm DNA per $\mathrm{ml}, 1 \% \mathrm{SDS}, 20 \mathrm{mM}$ sodium pyrophosphate) at $45^{\circ} \mathrm{C}$. Hybridization was carried out overnight in the same solution as above except that it contained $1 \times$ Denhardt's solution, with the remaining volume made up of diethyl pyrocarbonate-treated distilled water. Unincorporated $\left[\alpha^{32} \mathrm{P}\right] \mathrm{dCTP}$ was removed over a NucTrap push column (Stratagene, La Jolla, Calif.), and the DNA probe was added at approximately $10^{6} \mathrm{cpm}$ per $\mathrm{ml}$ of hybridization solution. Membrane blots were washed twice in $2 \times \mathrm{SSC}-0.1 \%$ SDS for $30 \mathrm{~min}$ each at $45^{\circ} \mathrm{C}$ followed by at least two washes in $0.1 \times \mathrm{SSC}-0.1 \%$ SDS at $55^{\circ} \mathrm{C}$ and sometimes at $65^{\circ} \mathrm{C}$. Autoradiographs were obtained by exposing the membranes to X-ray film, and hybridization was quantified by densitometry as described previously (27). All values were normalized by comparison to the $16 \mathrm{~S}$ and $23 \mathrm{~S}$ RNAs present in the ethidium bromide-stained gels prior to blotting.

Primer extension analysis of total RNA. Primer extension analyses of total RNA using two katB-specific oligonucleotide primers were performed as described previously $(4,29)$ with some modifications $(27)$. The oligonucleotide primers 5'-GCG ATA GGA CGA CCA TTA GC-3' and 5'-GTC CTG CTG TCT GGC TGT TT-3' were complementary to nucleotides 25 to 44 and 54 to 73 , respectively, of the katB gene coding region. A third oligonucleotide primer, 5'-ACC CGA CAA ATG TAG AG-3', complementary to nucleotides -89 to -73 upstream of the katB translation start codon was used in some experiments. The $5^{\prime}$ ends of the oligonucleotides were labelled with $\left[\gamma_{-}{ }^{32} \mathrm{P}\right] \mathrm{dATP}$ by standard protocols (29), and these were used as primers for the reverse transcriptase (RT) reaction.

Radiolabelled oligonucleotides (approximately $5 \times 10^{5} \mathrm{cpm}$ ) were precipitated with $50 \mu \mathrm{g}$ of total RNA. The resulting pellet was dried, suspended in buffer containing $80 \%$ deionized formamide, $400 \mathrm{mM} \mathrm{NaCl}, 1 \mathrm{mM}$ EDTA, and $40 \mathrm{mM}$ piperazine- $N, N^{\prime}$-bis(2-ethanesulfonic acid (PIPES) (pH 6.4), incubated at $85^{\circ} \mathrm{C}$ for $10 \mathrm{~min}$, and then annealed overnight at $40^{\circ} \mathrm{C}$. After ethanol precipitation and centrifugation, the pellet was dried, suspended in $20 \mu \mathrm{l}$ of RT buffer,
A

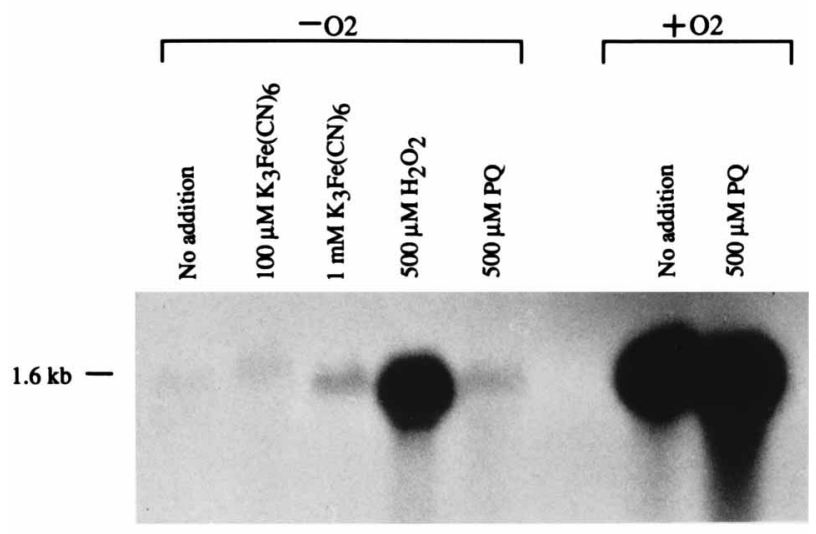

B

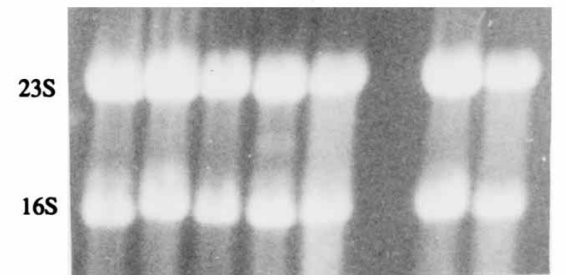

FIG. 1. Northern hybridization analysis of katB from mid-logarithmic-phase cultures of strain 638R of $B$. fragilis exposed to different oxidative stress conditions. (A) Autoradiograph of a Northern blot from the gel shown in panel B probed with the ${ }^{32} \mathrm{P}$-labelled $k a t B$-specific DNA fragment. Abbreviations: -O2, without oxygen (anaerobic); $+\mathrm{O} 2$, with oxygen (oxidative stress); PQ, paraquat. (B) Formaldehyde agarose gel containing $30 \mu \mathrm{g}$ of total RNA in each lane stained by ethidium bromide.

which contains $50 \mathrm{mM}$ Tris- $\mathrm{HCl}(\mathrm{pH} 8.3$ ), $75 \mathrm{mM} \mathrm{KCl,} 3 \mathrm{mM} \mathrm{MgCl} 2,10 \mathrm{mM}$ dithiothreitol, $1 \mathrm{mM}$ each of the four deoxynucleoside triphosphates, $100 \mu \mathrm{g}$ of actinomycin D per ml, and $10 \mathrm{U}$ of RNase inhibitor (Life Technologies). Then, 200 U of Superscript II Reverse Transcriptase (Life Technologies) was added, and the mixture was incubated at $37^{\circ} \mathrm{C}$ for $1 \mathrm{~h}$ and then at $42^{\circ} \mathrm{C}$ for $1 \mathrm{~h}$. The reaction was inactivated by the addition of $50 \mathrm{mM}$ EDTA followed by the addition of $250 \mathrm{mM} \mathrm{NaOH}$ at $65^{\circ} \mathrm{C}$ for $30 \mathrm{~min}$ to hydrolyze ribonucleic acids and then was neutralized with $250 \mathrm{mM} \mathrm{HCl}$. The reaction products were phenolchloroform extracted, precipitated, dried, and suspended in formamide loading buffer. The extended labelled product was electrophoresed on $6 \%$ polyacrylamide gels containing urea. A DNA sequencing ladder was prepared with a template encompassing the transcriptional start side region, using the same oligonucleotides that were used for the reverse transcription reactions.

\section{RESULTS}

Effect of oxidative stress on the expression of $\mathbf{k a t B}$. The regulation of $B$. fragilis catalase was examined for a variety of growth conditions using Northern blots probed with an internal $k a t B$-specific gene fragment. For all conditions tested, there was a single mRNA transcript of katB observed of approximately $1.6 \mathrm{~kb}$ in size. This is consistent with a monocistronic message coding for the 55,905-molecular-weight KatB subunit (25). The levels of katB mRNA increased dramatically following either the addition of hydrogen peroxide or exposure to oxygen for $60 \mathrm{~min}$ (Fig. 1). Both of these oxidative stress conditions appeared to induce synthesis of katB mRNA significantly. There was at least a 15 -fold increase observed after both $\mathrm{H}_{2} \mathrm{O}_{2}$ treatment and oxygen exposure as determined by densitometry analysis of the katB Northern filter blots. The addition of paraquat in the presence of oxygen did not significantly induce the synthesis of mRNA further, suggesting that 
A

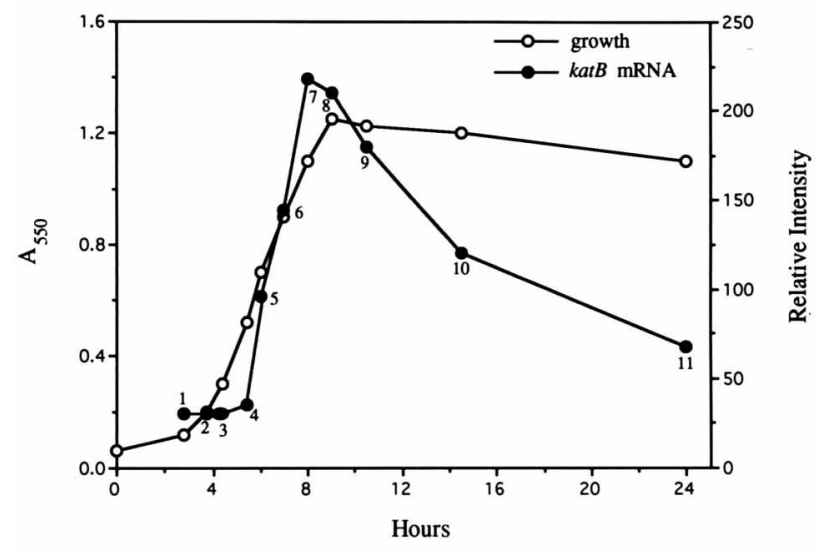

B

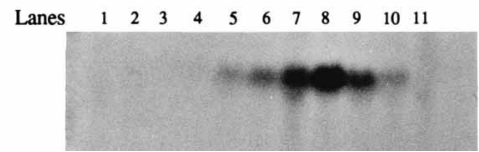

FIG. 2. (A) Growth and expression of $k a t B$ mRNA during anaerobic growth of $B$. fragilis 638R. (B) Autoradiograph following Northern hybridization of 30 $\mu \mathrm{g}$ of total RNA obtained at different time points. Cultures grown overnight were diluted 100-fold into BHIS medium and grown in the anaerobic chamber. Samples were taken at the times indicated in panel A to obtain RNA for the Northern hybridization shown in the lanes in panel B. The relative intensity was determined by densitometry analysis.

the aeration of the culture was sufficient for maximum expression of the katB gene. Under anaerobic conditions, the addition of the oxidant potassium ferricyanide at $100 \mu \mathrm{M}$ did not significantly ( $\leq 2$-fold) affect the levels of katB mRNA but there was a modest increase (3.5-fold) with $1 \mathrm{mM}$ potassium ferricyanide or with $500 \mu \mathrm{M}$ paraquat (Fig. 1).

Carbon or energy starvation control of catalase. Interestingly, a low level of katB transcript also seems to be present in the absence of oxygen during mid-logarithmic growth phase of $B$. fragilis cells. This observation and previous work showing that catalase activity was detected in anaerobically grown stationary-phase cells (25) led us to investigate the expression of $k a t B$ mRNA during the anaerobic growth of strain 638R. katB mRNA was expressed anaerobically in a growth-dependent manner, reaching maximum expression at late-log or early stationary phase, followed by a decrease during the stationary phase (Fig. 2). This suggested that catalase expression may also be influenced by the stationary-phase response or nutritional starvation generally associated with entry into stationary phase. Thus, to investigate whether nutritional starvation could modulate catalase mRNA levels, $B$. fragilis was grown in PY medium supplemented with a variety of fermentable and nonfermentable carbon sources and the levels of katB mRNA from cells in mid-logarithmic growth phase were determined. Figure 3 shows that in the absence of oxygen, the expression of katB mRNA was strongly repressed by glucose compared to the culture in basal PY medium. However, the addition of fumarate, succinate, pyruvate, or acetate to the PY medium had no repressing effect on $k a t B$. Glucose repression was abolished upon oxygen exposure, and the levels of mRNA increased dramatically. In fact, katB induction was to the same approximate levels for all oxygen-treated cultures, regardless of the carbon source (Fig. 3). These results indicate that katB is

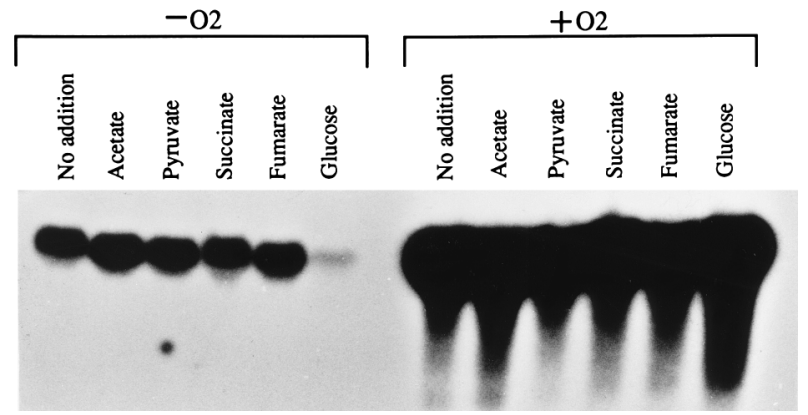

FIG. 3. Effects of carbon and energy sources on katB mRNA expression. Autoradiograph following Northern hybridization analysis of anaerobic $\left(-\mathrm{O}_{2}\right)$ or oxygen-stressed $\left(+\mathrm{O}_{2}\right)$ mid-logarithmic-phase cells of $B$. fragilis $638 \mathrm{R}$. Cells were grown anaerobically in PY medium supplemented with the indicated carbon sources. The cultures were then divided, and half of each culture was exposed to air for $1 \mathrm{~h}$ prior to sample collection.

regulated by two apparently independent signals, nutritional starvation and oxidative stress.

The results of an experiment designed to determine if fermentable carbon sources could inhibit the increase of katB message are in agreement with the carbon and energy starvation experiments (Fig. 4). Glucose, xylose, and nonfermentable fumarate were added to a culture growing in basal medium containing pyruvate. The addition of glucose resulted in a rapid stimulation of bacterial growth and a fivefold inhibition of katB mRNA within $30 \mathrm{~min}$. In the case of xylose, a slightly different result was observed. There was a lag period between the time of addition of xylose and the stimulation of growth, and the level of katB message at the 30-min time point was not significantly different than that of the pyruvate control. However, by $2 \mathrm{~h}$, the growth rate had increased and a 1.6-fold inhibition of $k a t B$ mRNA was seen. Following the addition of the nonfermentable carbon source fumarate, there was little effect on the growth rate and the levels of katB mRNA decreased only slightly.

To determine whether the starvation response was specific for carbon and energy sources or if starvation for different nutrients could induce the response, several additional experiments were carried out. In contrast to the carbon effects, phosphate limitation did not seem to affect the level of catalase mRNA. When $8 \mathrm{mM}$ phosphate was added to a phosphatelimited culture (growing with $0.08 \mathrm{mM}$ phosphate), a rapid increase in growth was observed and there was a slight increase in $k a t B$ mRNA compared to the phosphate-limited culture (data not shown). The effects of nitrogen and hemin on the expression of catalase mRNA were similar to phosphate limitation, and neither nitrogen nor hemin limitation resulted in higher levels of katB mRNA (data not shown). These results suggest that phosphate, nitrogen, or hemin starvation did not cause the same effect on catalase mRNA expression as seen with the carbon and energy sources.

Identification of the $k a t B$ promoter region. Primer extension analysis was used to identify the transcriptional start site for $k a t B$ in cells maintained under anaerobic conditions or oxidatively stressed. The results in Fig. 5A reveal that there was just one major start site used by cells stressed with either $\mathrm{H}_{2} \mathrm{O}_{2}$ or oxygen. Further, the addition of the redox cycling agent paraquat to anaerobic or oxygen-stressed cells did not alter the transcriptional start site. The major mRNA +1 was located at the guanosine nucleotide position $75 \mathrm{bp}$ upstream of the $k a t B$ translational start codon (Fig. 5 and 6).

It was of interest to determine if cells used the same tran- 

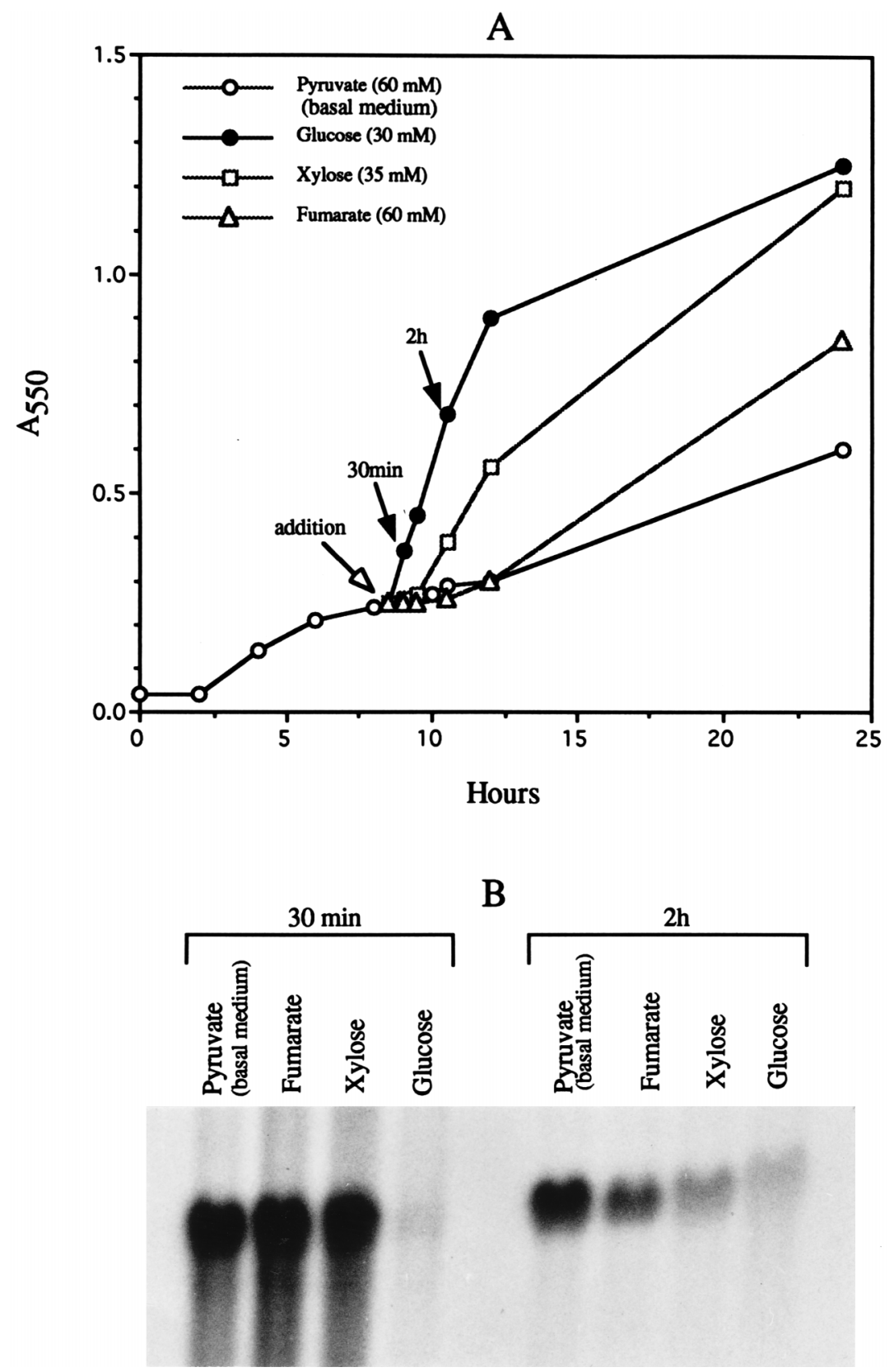

FIG. 4. Repression of katB mRNA expression by glucose. (A) Growth curve of culture grown in basal medium with pyruvate. At the time indicated by the white arrow, the culture was divided and the carbon and energy sources were added. (B) Autoradiograph of Northern blots probed with katB. Samples were obtained from the time points indicated by the black arrows in panel A.

scriptional start site when growing anaerobically under severe energy limitation and during oxidative stress. The results in Fig. 5B suggested that during severe energy starvation, there was a shift away from the major guanosine start site to one of the two A residues 3 or 4 bases closer to the translational start of $k a t B$. In contrast, anaerobic cells grown with glucose did not change start sites. When these cultures were exposed to oxygen, nearly all transcription initiated at the major guanosine start site, indicating that this was the start of the predominant oxidative stress transcript.

Analysis of the nucleotide sequence upstream of the katB transcription start site revealed that there are three inverted repeats in this region. The only other oxidative stress gene from $B$. fragilis for which the nucleotide sequence is known is superoxide dismutase. Interestingly, the comparison of these two sequences revealed that one imperfect inverted repeat sequence TGAAATnnnnnATTTGA (where $\mathrm{n}$ is any nucleotide), is present in the upstream region of both the sod and $k a t B$ gene (Fig. 6). Moreover, this inverted repeat overlaps with the predicted -35 region of the $k a t B$ gene promoter region. These results suggest that this repeat sequence may be a cis-acting nucleotide sequence element involved in the regulation of the $B$. fragilis catalase gene.

\section{DISCUSSION}

The study of the antioxidant mechanisms and ROS scavenging enzymes in an aerotolerant anaerobic bacterium such as $B$. 
$\mathbf{A}$

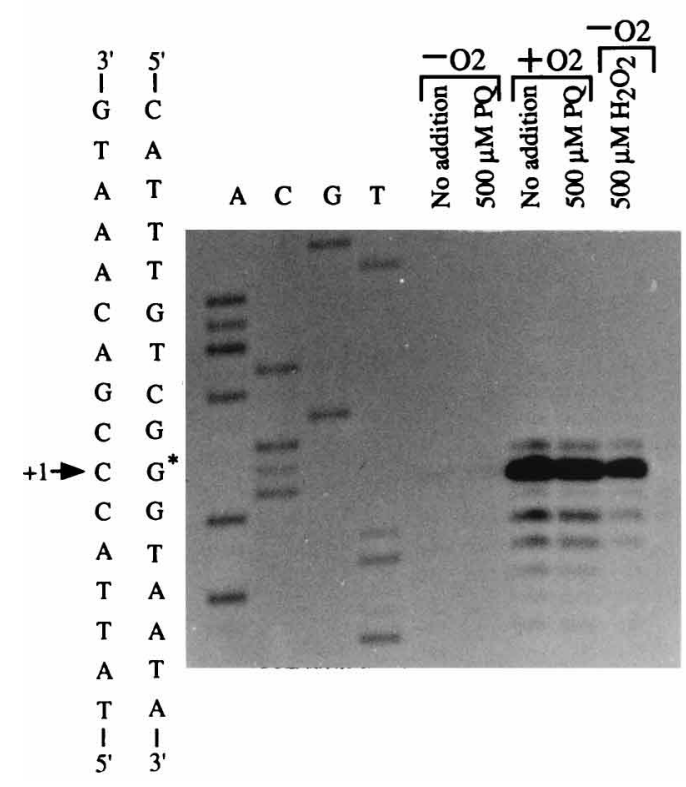

B

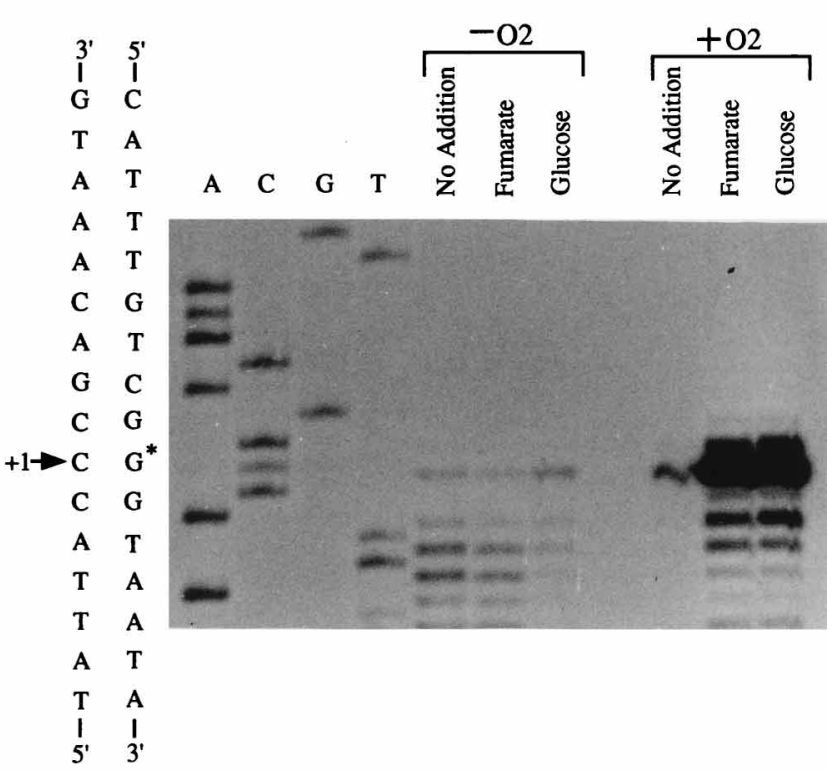

FIG. 5. Autoradiographs of primer extension analyses of katB during oxidative stress and carbon and energy limitations. (A) Total RNA was obtained from mid-logarithmic-phase cells of $B$. fragilis 638R grown in BHIS and then exposed to different oxidative stress conditions as indicated. Abbreviations: - O2, without oxygen (anaerobic); +O2, with oxygen (oxidative stress); PQ, paraquat. (B) Total RNA obtained from mid-logarithmic-phase cells of $B$. fragilis 638R grown anaerobically in PY medium alone (no addition) or supplemented with either fumarate or glucose and then exposed to oxygen. For both panels A and B, the nucleotide sequences of $k a t B$ obtained by using the same primer as used for the primer extension were run in parallel. The transcription start site for $k a t B$ is indicated $\left(\mathrm{G}^{*}\right)$.

fragilis may provide new insight into our understanding of the protective response to oxidative stress in all living organisms. First, because this is an anaerobic organism, it cannot utilize oxygen or change to an aerobic growth mode when shifted from anaerobic conditions. Thus, the response to oxygen exposure must be rapidly and fully induced, since diminishing cellular resources will prevent further significant expression of protective mechanisms. Second, the response may be programmed for a specific period of time that would maximize viability until appropriate anaerobic growth conditions are reestablished. Finally, the Bacteroides diverged very early from other eubacteria (35), which suggests that this bacterium would be a suitable organism for studying how different bacteria have independently developed highly regulated mechanisms against oxygen toxicity.

Regulation of the $B$. fragilis response to oxidative stress may be best examined through the use of a model system, and we have chosen catalase as a representative ROS enzyme. Previously it was shown that the KatB protein and activity were induced by oxidative stress and that this was part of a much larger physiological response involving the apparent induction of at least 28 new peptides (26). In the present report, results suggest that the katB catalase gene is regulated at the transcriptional level; however, a mechanism involving increased stability of the mRNA cannot be formally ruled out. The katB gene was transcribed as a monocistronic mRNA either following oxidative stress or during growth under carbon and energy limitations. Although the regulatory mechanism controlling the synthesis of catalase is not known, the strong induction of katB mRNA following oxidative stress is clearly consistent with it being part of a coordinated global oxidative stress response in $B$. fragilis. The induction of catalase mRNA in the absence of oxygen suggests that this enzyme may be important during starvation conditions to protect the cells against eventual oxygen exposure or to decompose $\mathrm{H}_{2} \mathrm{O}_{2}$ that may eventually be formed from stationary phase or dormancy metabolism. Consistent with this view is the fact that a $B$. fragilis catalase mutant is more likely to survive in stationary phase than the parent

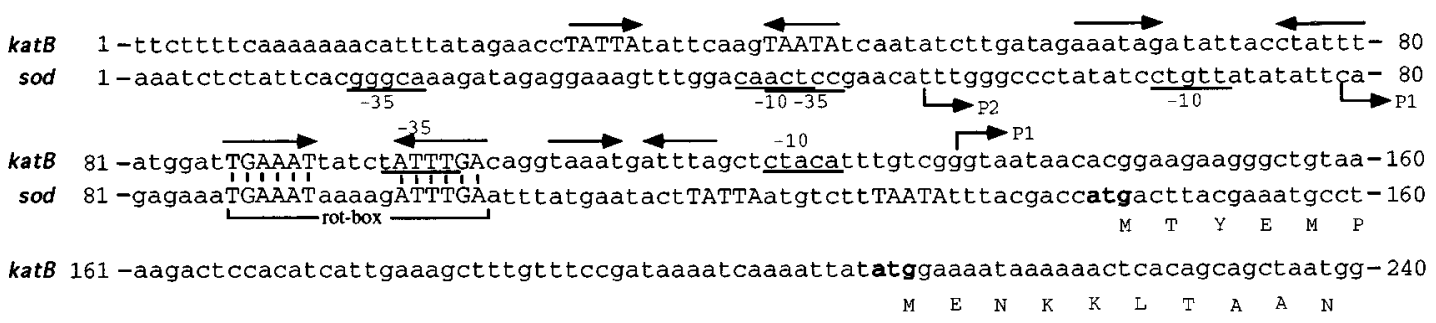

FIG. 6. Comparison of the nucleotide sequence upstream of the $B$. fragilis kat $B$ and $s o d$ genes. The putative -35 and -10 regions of the promoter regions of $k a t B$ and sod are underlined. Regions of dyad symmetry are shown by arrows over the sequence, and rot-box region is indicated (identical nucleotides are indicated by short vertical lines). Sequences of dyad symmetry present in $k a t B$ and $\operatorname{sod}$ are indicated by capital letters. The transcription start site for katB is at the G nucleotide 75 bp upstream of the translation start codon and is indicated by an arrow labelled P1 over the katb sequence. Two potential start sites for sod (26a) are shown by the arrows labelled P1 and P2 under the sequence of sod. The peptide start codon is shown in bold type. Only the first 10 codons of the katB and the first 6 codons of the sod N-terminal regions are shown, respectively. 
strain (unpublished data). A similar observation was made for an $E$. coli katE mutant which lacks the HPII catalase controlled by the stationary-phase regulator rpoS $(18,22)$.

Although the function of all catalases is to eliminate $\mathrm{H}_{2} \mathrm{O}_{2}$ by forming water and molecular oxygen, the regulation of this enzyme in procaryotes varies greatly among bacterial species (15). Different species regulate the synthesis of catalase according to their own specific needs and environmental conditions (15). In the case of E. coli and Salmonella typhimurium, there are two catalases, KatG (HPI) and KatE (HPII). The level of KatG increases approximately 10 -fold in response to $\mathrm{H}_{2} \mathrm{O}_{2}$ during exponential growth and is regulated by the OxyR protein, a member of the LysR family of regulatory proteins that is able to perform both sensor and transducer activities $(13,31)$. To a much less extent, KatG is also induced by the stationary-phase alternative sigma factor $\sigma^{\mathrm{s}}$ encoded by the $r p o S$ gene (12). In contrast, KatE increases its expression approximately 10 -fold at the entry of stationary phase under the control of $\sigma^{\mathrm{S}}$ and possibly other transcriptional factors $(19,22)$. Interestingly, $B$. fragilis possesses a single catalase enzyme which responded to both $\mathrm{H}_{2} \mathrm{O}_{2}$ and carbon and energy starvation signals and both responses appeared to be controlled by the same promoter region. In contrast, the Haemophilus influenzae catalase gene which shares $76 \%$ amino acid sequence identity and $66 \%$ nucleotide sequence identity with $\mathrm{katB}(25)$ is induced by $\mathrm{H}_{2} \mathrm{O}_{2}$ in mid-logarithmic-phase cells but is repressed in stationary phase (2). Consistent with this difference in regulation is the upstream regulatory region of $k a t B$ in $B$. fragilis which has diverged greatly from the upstream region of $H$. influenzae katE with nucleotide sequence identity of only $46 \%$.

As mentioned above, a global oxidative stress regulatory mechanism in B. fragilis has not yet been elucidated. However, the finding of an inverted repeat sequence in both the regulatory region of $k a t B$ and the superoxide dismutase gene sod makes this sequence, TGAAATnnnnnATTTGA, a strong candidate for a DNA binding protein recognition site involved in the regulation of oxidative stress genes. This sequence, tentatively designated the rot box (rot for response to oxygen toxicity), has not been found in regulatory regions of other $B$. fragilis genes available in the database (data not shown). The potential role this sequence plays in the regulation of $B$. fragilis oxidative stress gene expression is presently under investigation and will be clarified as more oxidative stress genes of $B$. fragilis are identified.

Two distinct mechanisms affected the expression of $\mathrm{katB}$, oxidative stress and growth phase or carbon and energy dependence. Interestingly, both forms of control utilized the same or overlapping transcription promoter. Regulation by the availability of a carbon or energy source was oxygen independent, and the levels of katB mRNA decreased immediately when glucose was added to anaerobic, carbon- or energystarved cultures. $k a t B$ was more slowly repressed by xylose, a more slowly fermented sugar. Consistent with this observation, during phosphate- or nitrogen-limited growth, there was clearly excess glucose and levels of $k a t B$ mRNA were the same or somewhat higher when an excess amount of the limiting nutrient was added to the culture. Thus, the carbon or energy source control seems to be restricted to carbon and energy sources and not other forms of nutritional limitation. This confirms and adds to a previous report showing that catalase activity in $B$. fragilis is abolished by fermentable carbohydrate (8). The second form of regulation is oxygen or ROS dependent, and this control is dominant in that oxidative stress resulted in high levels of $k a t B$ mRNA overcoming the glucose repression mechanism (Fig. 3). This suggests that catalase syn- thesis is necessary to protect $B$. fragilis against toxic $\mathrm{H}_{2} \mathrm{O}_{2}$ that is formed under aerobic conditions. Dual regulatory mechanisms of catalase expression have also been demonstrated for the $B$. subtilis katA catalase gene. In this case, transcription initiation occurs at the same site under two independent mechanisms, the $\mathrm{H}_{2} \mathrm{O}_{2}$-inducible regulation and the sporulation regulatory genes $\operatorname{spo} 0 A$ and $a b r B(3)$.

At this point, it is not known if $k a t B$ is controlled by a repressor or activator mechanism such as $\operatorname{oxy} R$ nor is it known whether oxygen or $\mathrm{H}_{2} \mathrm{O}_{2}$ is the signal which initiates the response. It is unlikely that an increase in the oxidation-reduction potential (Eh) of the medium has a direct effect on the transcription activation of katB gene, as only a low level of mRNA was detected in the presence of an oxidant (potassium ferricyanide). This suggests that the presence of either oxygen or ROS but not an increase in medium Eh is the important signal for catalase mRNA expression. This is consistent with previous reports which showed that molecular oxygen but not high Eh inhibited growth and survival of anaerobes $(23,34)$.

The oxidative stress response in $B$. fragilis may be an advantageous adaptive mechanism during the initial steps of an infectious process when oxygenated human tissues will be encountered for a time until anaerobic conditions suitable for multiplication and growth can be established. It has been reported that adaptation to oxidative stress conditions is important for pathogenic facultative intestinal bacteria such as $E$. coli and $S$. typhimurium to survive not only in aerobic environments but also for resistance to the oxidative burst of macrophages and phagocytic cells of the immune system when they leave the anaerobic human intestinal tract to cause extraintestinal infections $(6,31)$. Hydrogen peroxide generation within phagosomes is one of the important active oxygen species produced by macrophages to kill invading microorganisms $(10,28)$, and a potential role of the catalase enzyme in some pathogenic organisms is to eliminate $\mathrm{H}_{2} \mathrm{O}_{2}$ generated in the infected tissues (15). With regard to $B$. fragilis, the presence of a functional catalase enzyme was essential for survival in the presence of an exogenous source of hydrogen peroxide in vitro (26) and the role it plays in vivo remains to be investigated.

\section{ACKNOWLEDGMENTS}

This work was supported by grant 9513-ARG-0038 from the North Carolina Biotechnology Center.

We thank G. Tribble and D. Smalley for critical reading of the manuscript and M. Malamy for helpful discussions.

\section{REFERENCES}

1. Aiba, H., S. Adhya, and B. deCrombrugghe. 1981. Evidence for two functional gal promoters in intact Escherichia coli. J. Biol. Chem. 256:1190511910.

2. Bishai, W. R., H. O. Smith, and G. J. Barcak. 1994. A peroxide/ascorbateinducible catalase from Haemophilus influenzae is homologous to the Escherichia coli katE gene product. J. Bacteriol. 176:2914-2921.

3. Bol, D. K., and R. E. Yasbin. 1994. Analysis of the dual regulatory mechanisms controlling expression of the vegetative catalase gene of Bacillus subtilis. J. Bacteriol. 176:6744-6748.

4. Boorstein, W. R., and E. A. Craig. 1989. Primer extension analysis of RNA. Methods Enzymol. 180:347-369.

5. Christman, M. F., R. w. Morgan, F. S. Jacobson, and B. N. Ames. 1985. Positive control of a regulon for defenses against oxidative stress and some heat-shock proteins in Salmonella typhimurium. Cell 41:753-762.

6. Demple, B. 1991. Regulation of bacterial oxidative stress genes. Annu. Rev. Genet. 25:315-337.

7. Farr, S. B., and T. Kogoma. 1991. Oxidative stress responses in Escherichia coli and Salmonella typhimurium. Microbiol. Rev. 55:561-585.

8. Gregory, E. M., B. J. Veltri, D. L. Wagner, and T. D. Wilkins. 1977. Carbohydrate repression of catalase synthesis in Bacteroides fragilis. J. Bacteriol. 129:534-535.

9. Hassan, H. M., and I. Fridovich. 1978. Regulation of the synthesis of catalase and peroxidase in Escherichia coli. J. Biol. Chem. 253:6445-6450. 
10. Hassett, D. J., and M. S. Cohen. 1989. Bacterial adaptation to oxidative stress: implications for pathogenesis and interaction with phagocytic cells. FASEB J. 3:2574-2582.

11. Holdeman, L. V., E. P. Cato, and W. E. C. Moore. 1977. Anaerobe laboratory manual, 4th ed. Virginia Polytechnic Institute and State University, Blacksburg, Va.

12. Ivanova, A., C. Miller, G. Glinsky, and A. Eisenstark. 1994. Role of rpoS $(\mathrm{kat} F)$ in oxyR-dependent regulation of hydroperoxidase I in Escherichia coli. Mol. Microbiol. 12:571-578.

13. Kullik, I., M. B. Toledano, L. A. Tartaglia, and G. Storz. 1995. Mutational analysis of the redox-sensitive transcriptional regulator OxyR: regions important for oxidation and transcriptional activation. J. Bacteriol. 177:12751284.

14. Lange, R., and R. Hengge-Aronis. 1991. Identification of a central regulator of stationary-phase gene expression in Escherichia coli. Mol. Microbiol. 5: 49-59.

15. Loewen, P. C. 1997. Bacterial catalases, p. 273-308. In J. G. Scandalios (ed.), Oxidative stress and the molecular biology of antioxidant defenses. Cold Spring Harbor Laboratory Press, Cold Spring Harbor, N.Y.

16. Loewen, P. C., J. Switala, and B. L. Triggs. 1985. Catalases HPI and HPII in E. coli are induced independently. Arch. Biochem. Biophys. 243:144-149.

17. Loewen, P. C., and R. Hengge-Aronis. 1994. The role of the sigma factor $\sigma^{\mathrm{S}}$ (KatF) in bacterial global regulation. Annu. Rev. Microbiol. 48:53-80.

18. McCann, M. P., J. P. Kidwell, and A. Martin. 1991. The putative $\sigma$ factor KatF has a central role in development of starvation-mediated general resistance in Escherichia coli. J. Bacteriol. 173:4188-4194.

19. Meir, E., and E. Yagil. 1990. Regulation of Escherichia coli catalases by anaerobiosis and catabolite repression. Curr. Microbiol. 20:139-143.

20. Morgan, R. W., M. F. Christman, F. S. Jacobson, G. Storz, and B. N. Ames. 1986. Hydrogen peroxide-inducible proteins in Salmonella typhimurium overlap with heat shock and other stress proteins. Proc. Natl. Acad. Sci. USA 83:8059-8063.

21. Morris, J. G. 1980. Oxygen tolerance/intolerance of anaerobic bacteria, p. 7-15. In G. Gottschalk, N. Penning, and H. Werner (ed.), Anaerobes and anaerobic infections. Proceedings of Symposia held at the XII International Congress of Microbiology in Munich. Gustav Fisher Verlag, Stuttgart, Germany.

22. Mulvey, M. R., J. Switala, A. Borys, and P. C. Loewen. 1990. Regulation of transcription of katE and katF in Escherichia coli. J. Bacteriol. 172:67136720 .

23. Onderdonk, A. B., J. Johnston, J. W. Mayhew, and S. L. Gorbach. 1976. Effect of dissolved oxygen and Eh on Bacteroides fragilis during continuous culture. Appl. Environ. Microbiol. 31:168-172.

24. Privitera, G., A. Dublanchet, and M. Sebald. 1979. Transfer of multiple antibiotic resistance between subspecies of Bacteroides fragilis. J. Infect. Dis. 139:97-101.

25. Rocha, E. R., and C. J. Smith. 1995. Biochemical and genetic analyses of a catalase from the anaerobic bacterium Bacteroides fragilis. J. Bacteriol. 177: 3111-3119.

26. Rocha, E. R., T. Selby, J. P. Coleman, and C. J. Smith. 1996. The oxidative stress response in an anaerobe, Bacteroides fragilis: a role for catalase in protection against hydrogen peroxide. J. Bacteriol. 178:6895-6903.

26a.Rocha, E. R., and C. J. Smith. Unpublished data.

27. Rogers, M. B., T. K. Bennett, C. M. Payne, and C. J. Smith. 1994. Insertional activation of cep $A$ leads to high-level $\beta$-lactamase expression in Bacteroides fragilis clinical isolates. J. Bacteriol. 176:4376-4384.

28. Roos, D. 1991. The involvement of oxygen radicals in microbicidal mechanisms of leukocytes and macrophages. Klin. Wochenschr. 69:975-980.

29. Sambrook, J., E. F. Fritsch, and T. Maniatis. 1989. Molecular cloning: a laboratory manual, 2nd ed. Cold Spring Harbor Laboratory Press, Cold Spring Harbor, N.Y.

30. Smith, C. J. 1985. Characterization of Bacteroides ovatus plasmid pBI136 and structure of its clindamycin resistance region. J. Bacteriol. 1611069-1073.

31. Storz, G., L. A. Tartaglia, S. B. Farr, and B. N. Ames. 1990. Bacterial defenses against oxidative stress. Trends Genet. 6:363-368.

32. Storz, G., and L. A. Tartaglia. 1992. OxyR: a regulator of antioxidant genes. J. Nutr. 122(Suppl.3):627-630.

33. Varel, V. H., and M. P. Bryant. 1974. Nutritional features of Bacteroides fragilis subsp. fragilis. Appl. Microbiol. 18:251-257.

34. Walden, W. C., and D. J. Hentges. 1975. Differential effects of oxygen and oxidation-reduction potential on the multiplication of three species of anaerobic intestinal bacteria. Appl. Microbiol. 30:781-785.

35. Weisburg, W. G., Y. Oyaizu, H. Oyaizu, and C. R. Woese. 1985. Natural relationship between Bacteroides and flavobacteria. J. Bacteriol. 164:230 236. 